\title{
BMJ
}

\section{Imported malaria and high risk groups: observational study using UK surveillance data 1987-2006}

\author{
Adrian D Smith, specialist registrar in public health, ${ }^{1}$ David J Bradley, emeritus professor of tropical \\ hygiene, ${ }^{1,2}$ Valerie Smith, malaria travel adviser, ${ }^{1}$ Marie Blaze, malaria travel adviser, ${ }^{1}$ Ron H Behrens, senior \\ lecturer, ${ }^{2}$ Peter L Chiodini, director, Malaria Reference Laboratory, ${ }^{1,2}$ Christopher J M Whitty, professor of \\ international health ${ }^{1,2}$
}

${ }^{1}$ HPA Malaria Reference Laboratory, London School of Hygiene and Tropical Medicine, London WC1E 6AU

${ }^{2}$ Department of Infectious and Tropical Diseases, London School of Hygiene and Tropical Medicine Correspondence: A Smith, Division of Public Health and Primary Care, University of Oxford, Oxford OX3 7LF adrian.smith@dphpc.ox.ac.uk

Cite this as: $B M J$ 2008:337:a120 doi:10.1136/bmi.a120

\section{ABSTRACT}

Objective To examine temporal, geographic, and sociodemographic trends in case reporting and case fatality of malaria in the United Kingdom.

Setting National malaria reference laboratory surveillance data in the UK.

Design Observational study using prospectively gathered surveillance data and data on destinations from the international passenger survey.

Participants 39300 cases of proved malaria in the UK between 1987 and 2006.

Main outcome measuresPlasmodium species; sociodemographic details (including age, sex, and country of birth and residence); mortality; destination, duration, and purpose of international travel; and use of chemoprophylaxis.

Results Reported cases of imported malaria increased significantly over the 20 years of the study; an increasing proportion was attributable to Plasmodium falciparum $(P$ falciparum/ $P$ vivax reporting ratio 1.3:1 in 1987-91 and $5.4: 1$ in 2002-6). $P$ vivax reports declined from 3954 in 1987-91 to 1244 in 2002-6. Case fatality of reported $P$ falciparum malaria did not change over this period $(7.4$ deaths per 1000 reported cases). Travellers visiting friends and relatives, usually in a country in Africa or Asia from which members of their family migrated, accounted for 13 215/20 488 (64.5\%) of all malaria reported, and reports were geographically concentrated in areas where migrants from Africa and South Asia to the UK have settled. People travelling for this purpose were at significantly higher risk of malaria than other travellers and were less likely to report the use of any chemoprophylaxis (odds ratio of reported chemoprophylaxis use $0.23,95 \%$ confidence interval 0.21 to 0.25 ).

Conclusions Despite the availability of highly effective preventive measures, the preventable burden from falciparum malaria has steadily increased in the UK while vivax malaria has decreased. Provision of targeted and appropriately delivered preventive messages and services for travellers from migrant families visiting friends and relatives should be a priority.

\section{INTRODUCTION}

Globally, malaria is estimated to affect 500 million people and to cause more than one million deaths a year. ${ }^{1}$ Malaria acquired in endemic regions and imported into non-endemic countries accounts for a considerable and largely preventable burden of morbidity and mortality throughout Europe every year. Most general practitioners are involved in advising on prophylaxis against malaria, and most clinicians in the United Kingdom will be involved in diagnosing or treating cases of malaria. The increasing accessibility of international air travel and changing preferences for travel destinations mean that more people visit regions endemic for malaria, and they do so increasingly regularly. ${ }^{2}$ Travellers to endemic areas can reduce their risk of malaria substantially by adopting preventive measures: avoiding mosquito bites and using appropriate chemoprophylaxis. ${ }^{3}$ Effective uptake of such measures is, however, largely dependent on the traveller's recognition and understanding of the risk. This in turn depends on an accurate risk assessment by healthcare workers who advise them; these risks change over time with shifts in the global epidemiology of malaria, changes in travel habits and patterns of migration (visits to friends and relatives are a common reason for travel), and changes in patterns of drug resistance.

We examined malaria notified in the UK in 1987 to 2006 inclusive, with the aim of identifying important trends and at risk groups to assist people advising travellers (mainly general practitioners) and those seeing unwell returned travellers (hospital doctors and general practitioners). We hypothesised that the group of travellers descended from migrant families visiting friends and relatives might be particularly at risk.

\section{METHODS}

The Malaria Reference Laboratory, part of the Health Protection Agency, provides reference and diagnostic parasitology services and maintains the national surveillance database of reported cases of malaria in the UK. Malaria surveillance is a passive detection 


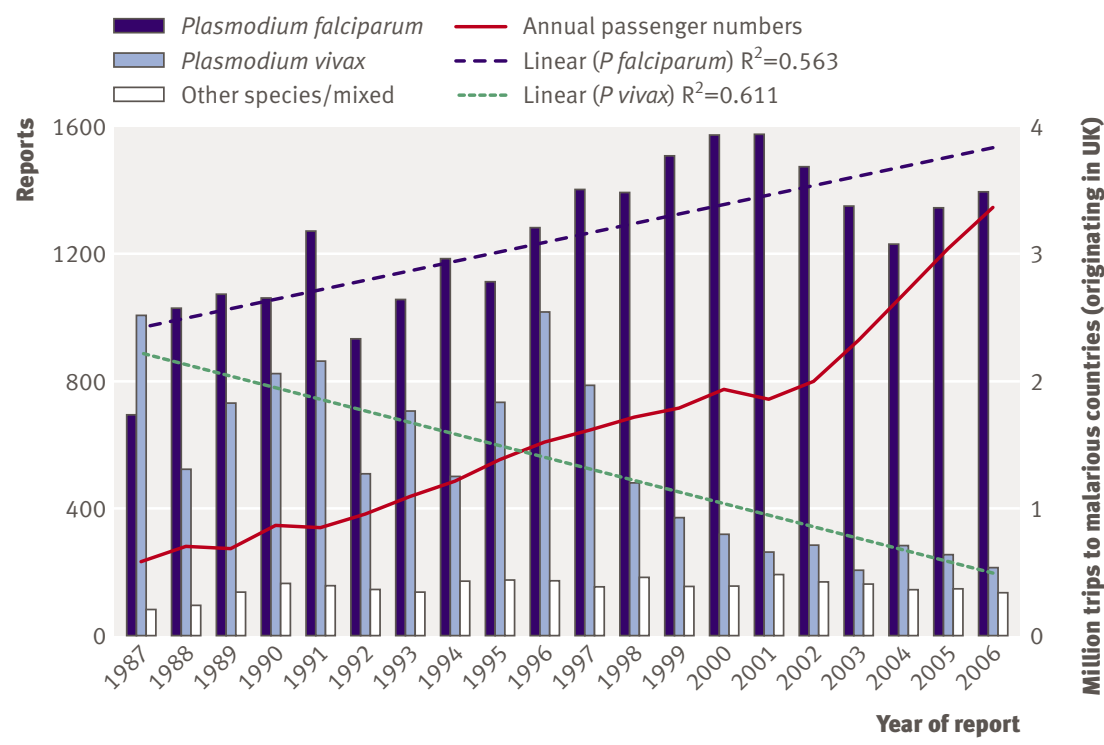

Fig 1| Reported cases of malaria, 1987 to 2006

system that identifies cases from statutory notification (through local authorities) and from clinicians who send standardised malaria reports to the Malaria Reference Laboratory, usually accompanied by blood films for laboratory verification. Systems for case ascertainment for malaria in the UK are thought to be among the most effective in the world. ${ }^{4}$ Case definition, which remained identical over the period covered by this study, requires parasitological confirmation (blood films or tissue histology). Cases treated presumptively or solely reliant on alternative means of diagnosis (such as antigen tests) are not included. The notifying laboratory and clinician are requested to provide further information-personal details (date of birth, sex, country of birth, country of usual residence), details of travel (date of arrival in UK, country or region visited, purpose of travel, duration of travel), prophylaxis taken, and details of illness (date of onset, date of treatment, and method of diagnosis). Methods of case detection, reporting, and transcribing and the information requested from care providers used for this analysis remained unchanged between 1987 and 2006.

We included all reported episodes of malaria in the UK from 1 January 1987 to 31 December 2006 to provide 20 consecutive years. Supplementary information came from records of death certification for all malaria associated deaths and from records of postmortem findings where available. We entered data into dBase IV and used Microsoft Access 10 for cleaning and validation, including identification of duplicates and audit for transcription errors. Estimates of annual residential population denominators for England and Wales, Scotland, and Northern Ireland for the period 1987-2006 came from respective national statistical collections..$^{5-7}$ Data on annual passenger numbers from the UK to individual "malarious countries" (as defined by the World Health Organization ${ }^{8}$ ), by purpose of travel, to selected countries in Africa and South Asia came from the international passenger survey for the years 1987 to 2006. This is a questionnaire based survey of a $0.2 \%$ stratified sample of travellers using British ports; detailed survey methods are described elsewhere. ${ }^{9}$ We did not analyse similar information for visitors to the UK.

We used Stata 10 for data analysis. We used Pearson's $\chi^{2}$ and Mantel-Haenszel methods for bivariate analysis of categorical variables, with KruskallWallis test for equality of populations for comparison of non-normally distributed continuous variables. We used linear regression for analysis of linear trend. For bivariate analyses for which data were incomplete, we compared missing values with collected values. Where reported, confidence intervals are $95 \%$ and $\mathrm{P}$ values are two tailed.

\section{RESULTS}

Between 1987 and 2006, 39300 cases of malaria were reported to the Malaria Reference Laboratory. Data were largely complete for central variables (age 96\%, sex $94 \%$, date of diagnosis $98 \%$, outcome $99 \%$ ) but less complete for some supplementary information (country of visit $88 \%$, purpose of travel $71 \%$, country of birth $64 \%$, prophylaxis use $62 \%$ ). The median age of cases was 31 years, and 38\% were female. Malaria was attributable to a single species in $98.7 \%$ of cases: $P$ falciparum 24859 (63\%) cases, P vivax 10904 (28\%), P ovale $6 \%, P$ malariae $1.5 \%$, and one case of $P$ knowlesi. Table 1 shows mortality by species and time period.

The pattern of malaria species has changed markedly over the study period. Reports of Pfalciparumincreased through the study period (linear regression: $\beta=+27.4$ notifications/year, $\mathrm{P}<0.0001)$; increases for Povale and

Table 1| Reported cases of malaria and deaths from Plasmodium falciparum malaria, 1987-2006

\begin{tabular}{|c|c|c|c|c|c|c|c|c|c|c|c|c|c|}
\hline \multirow[b]{2}{*}{ Period } & \multicolumn{7}{|c|}{ Reported malaria cases } & \multicolumn{4}{|c|}{$\begin{array}{c}\text { Reported case rate, per million UK } \\
\text { population }\end{array}$} & \multicolumn{2}{|c|}{ Deaths due to $P$ falciparum } \\
\hline & Pf & Pv & Po & $\mathrm{Pm}$ & Mixed & $\begin{array}{l}\text { Species not } \\
\text { confirmed }\end{array}$ & Total & Pf & Pv & Po & $\mathrm{Pm}$ & No & $\begin{array}{c}\text { Case fatality } \\
\text { (per } 1000 \text { cases) }\end{array}$ \\
\hline $1987-91$ & 5120 & 3954 & 513 & 106 & 186 & 12 & 9891 & 17.9 & 13.9 & 1.8 & 0.4 & 35 & 6.8 \\
\hline $1992-6$ & 5546 & 3475 & 638 & 152 & 169 & 1 & 9981 & 19.2 & 12.0 & 2.2 & 0.5 & 41 & 7.4 \\
\hline $1997-2001$ & 7440 & 2231 & 675 & 160 & 80 & 6 & 10592 & 25.4 & 7.6 & 2.3 & 0.6 & 59 & 7.9 \\
\hline $2002-6$ & 6753 & 1244 & 610 & 153 & 69 & 6 & $8836^{*}$ & 22.5 & 4.2 & 2.0 & 0.5 & 48 & 7.1 \\
\hline Total & 24859 & 10904 & 2436 & 571 & 504 & 25 & 39300 & 21.3 & 9.3 & 2.1 & 0.5 & 183 & 7.4 \\
\hline
\end{tabular}

$\mathrm{Pf}=$ Plasmodium falciparum; $\mathrm{Pm}=$ Plasmodium malariae; $\mathrm{Po}=$ Plasmodium ovale; $\mathrm{Pv}=$ Plasmodium vivax.

*Includes one case of $P$ knowlesi. 
$P$ malariae were less pronounced. In contrast, reports of $P$ vivax declined over the study period (linear regression: $\beta=-36.2$ notifications/year, $\mathrm{P}<0.0001$ ) (fig 1 ). The ratio of Pfalciparum to Pvivax infections increased from 1.3:1 in $1987-91$ to $5.4: 1$ in 2002-6. Table 2 shows region of travel where malaria was acquired, by species; $96 \%$ of falciparum malaria was acquired in Africa, whereas $80 \%$ of vivax malaria came from South Asia.

Table 3 shows data on reason for travel. Where reason for travel was known, 20488 cases, or $75 \%$ of imported cases, occurred in UK travellers (visitors from the UK to malarious countries); the remainder were among visitors to the UK. The number of journeys to malarious countries from the UK increased markedly (from 593000 visits in 1987 to 2.6 million visits in 2004), but the median duration of visits to malarious areas of cases decreased (1987-91, 42 days; 1992-6, 35 days; 1997-2001, 28 days; 2002-6, 28 days). Of the UK travellers whose reason for travel was known, 13215 (64.5\%, 95\% confidence interval 64\% to $65 \%$ ) had travelled to visit friends or relatives in their own or their families' country of origin. Most, but not all, of these people were visiting countries where their family had some degree of ethnic origin. The risk of malaria per episode of travel from the UK decreased between 1987 and 2006 for all species of malaria, most notably for Pvivax (fig 2).

Of the 34359 cases with reported travel history, $24599(71.6 \%, 71 \%$ to $72 \%)$ occurred after travel to Africa; this included 20774 of 21541 (96.4\%, 96\% to $97 \%$ ) cases of falciparum malaria. Sixty seven per cent of malaria in UK travellers arose after travel to west Africa; travel to Nigeria and Ghana accounted for 54\% of all imported $P$ falciparum. Of those people who acquired malaria in west Africa, 76\% were visiting friends or relatives in their own or their families' country of origin, whereas tourism was the most common purpose of travel for people visiting southern Africa (48\%) and east Africa (44\%). People who made trips to visit family in Africa were significantly more likely to have acquired malaria than those travelling for other reasons (risk ratio of reports per 10000 trips $=3.65,95 \%$ confidence interval 3.5 to 3.8 ; $\mathrm{P}<0.0001)$

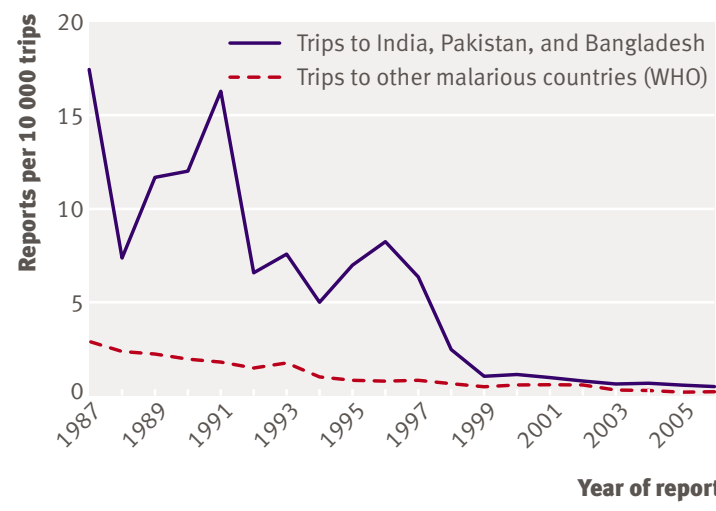

Fig 2 | Risk of reported Plasmodium vivax per travel episode to regions endemic for malaria

Travel to South Asia accounted for 8452 cases, $24.6 \%,(24 \%$ to $25 \%)$ of imported malaria, of which $92 \%$ was Pvivax. Over the study period, imported cases from this region declined significantly for all species of malaria despite a sustained increase in volume of travel. From 1987 to 1991, 3036 vivax cases arose from the Indian subcontinent, accounting for $31 \%$ of all UK malaria. By 2002-6, this had decreased to 705 cases (8\% of all UK malaria). Of cases in which the purpose of travel was reported, $89 \%$ of UK travellers visiting South Asia had done so to visit family and friends. People travelling for this reason were at significantly higher risk of acquiring malaria than other travellers (risk ratio of reported cases per 10000 trips $=7.9,7.2$ to 8.6; $\left.\chi^{2} \mathrm{P}<0.0001\right)$.

Of UK travellers with complete records (17 129), only $42 \%$ reported taking any form of chemoprophylaxis against malaria during their period of travel. Significant differences existed in the use of chemoprophylaxis (including non-standard drugs) according to the geographical origin of cases (table 4), and people who had visited family in their country of origin were less likely to report the use of any prophylaxis than other travellers (Mantel-Haenszel odds ratio adjusted for age and sex $=0.23,95 \%$ confidence interval 0.20 to 0.25). Among reported cases in people who travelled to sub-Saharan Africa between 1999 and 2006, over which period consistent recommendations on

Table 2 | Reported cases of malaria 1987-2006, by global region visited (where reported ${ }^{\star}$ ). Values are numbers (percentages)

\begin{tabular}{|c|c|c|c|c|c|}
\hline Region & Plasmodium falciparum & Plasmodium vivax & $\begin{array}{c}\text { Plasmodium } \\
\text { ovale }\end{array}$ & $\begin{array}{l}\text { Plasmodium } \\
\text { malariae }\end{array}$ & Total \\
\hline Africa & $20774(96.4)$ & $950(9.7)$ & $2058(98.0)$ & $480(98.0)$ & 24599 \\
\hline South Asiał & $517(2.4)$ & $7813(80.1)$ & $23(1.1)$ & $3(0.6)$ & 8452 \\
\hline Far East and South East Asia & $114(0.5)$ & $387(4.0)$ & $7(0.3)$ & $2(0.4)$ & 524 \\
\hline Central and South America & $35(0.2)$ & $304(3.1)$ & $3(0.1)$ & $3(0.6)$ & 350 \\
\hline Oceania & $46(0.2)$ & $263(2.7)$ & $7(0.3)$ & $1(0.2)$ & 333 \\
\hline Middle East & $51(0.2)$ & $39(0.4)$ & $3(0.1)$ & $1(0.2)$ & 97 \\
\hline Caribbean & $4(0.01)$ & 0 & 0 & 0 & 4 \\
\hline Total & 21541 & 9756 & 2101 & 490 & 34359 \\
\hline
\end{tabular}

*Excludes 4927 reports with no travel information reported and 14 reports with no known history of travel.

tIncludes one $P$ knowlesi,455 mixed species, and 15 unconfirmed species reports.

$\ddagger$ Afghanistan, Burma (Myanmar), Bhutan, India, Pakistan, Bangladesh, Nepal, and Sri Lanka. 
Table 3| Purpose of travel among reported cases of malaria, 1987-2006 (where reported*)

\begin{tabular}{|c|c|c|c|c|}
\hline & $\begin{array}{l}\text { Median (interquartile } \\
\text { range) duration of stay } \\
\text { (days) }\end{array}$ & Cases & $\begin{array}{l}\text { Deaths due to } \\
\text { Plasmodium } \\
\text { falciparum }\end{array}$ & $\begin{array}{c}\text { Percentage }(95 \% \mathrm{Cl}) \\
\text { cases reporting use of } \\
\text { prophylaxis* (limited } \\
\text { sample) }\end{array}$ \\
\hline \multicolumn{5}{|l|}{ Travel originating in UK } \\
\hline \multicolumn{5}{|l|}{ Travel originating outside UK } \\
\hline $\begin{array}{l}\text { Visiting family in country of } \\
\text { origin }\end{array}$ & $28(21-58)$ & 13215 & 25 & 28.4 (27.5 to 29.2$)$ \\
\hline Holiday to malarious country & $21(14-56)$ & 4029 & 72 & $68.5(67.0$ to 70.0$)$ \\
\hline Business/professional travel & $60(21-168)$ & 2105 & 24 & $61.6(59.4$ to 63.8$)$ \\
\hline Foreign student in UK & $28(15-70)$ & 548 & 0 & NA \\
\hline British armed forces & $46(28-110)$ & 374 & 1 & $92.6(89.1$ to 95.1$)$ \\
\hline $\begin{array}{l}\text { Children visiting parents } \\
\text { living abroad }\end{array}$ & $28(21-42)$ & 148 & 0 & 46.6 (37.9 to 55.4$)$ \\
\hline Civilian sea/air crew & $14(7-81)$ & 69 & 2 & $43.6(30.0$ to 57.7$)$ \\
\hline Foreign visitor ill while in UK & 28 & 3331 & 15 & NA \\
\hline New entrant to UK & NA & 2602 & 3 & NA \\
\hline UK citizen living abroad & NA & 1010 & 15 & $46.8(43.6$ to 50.1$)$ \\
\hline
\end{tabular}

$\mathrm{NA}=$ not applicable.

*Excludes 11869 reports and 26 deaths for which purpose of travel was not stated or travel had not occurred.

prophylactic drugs for this region were made, only 7\% of people visiting friends or relatives in their own or their families' country of origin reported having used recommended drugs, compared with $24 \%$ of people travelling for other reasons $\left(\chi^{2} \mathrm{P}<0.0001\right)$.

Probably reflecting the distribution of first generation and second generation immigrant groups, a striking geographical distribution of cases occurs in the UK (table 5). Forty one per cent of all cases of malaria in the UK, and $65 \%$ of cases of $P$ falciparum malaria, occurred in London residents or visitors to London, whereas most $(68 \%)$ cases of $P$ vivax were reported from other regions of the UK, notably the West Midlands (a region encompassing the densely populated conurbations of Birmingham, Wolverhampton, Coventry, and Stoke-on-Trent). The seasonality of $P$ falciparum cases shows a bimodal pattern, with peaks in January and September, mirroring patterns of travel to destinations where transmission of $P$ falciparum occurs throughout the year (fig 3). By contrast, patterns of monthly $P$ vivax reporting show a single summer peak, paralleling the peak transmission periods of malaria in much of India and Pakistan.

Mortality data show that 183 malaria related deaths occurred over the period of the study, giving an overall case fatality rate for $P$ falciparum malaria of $7.4(95 \%$

Table 4 | Use of chemoprophylaxis* among travellers from UK, by region of birth place

\begin{tabular}{lccc} 
& & & Prophylaxis taken \\
\cline { 3 - 4 } Region of birth & Cases & Yes & Percentage $(95 \% \mathrm{Cl})$ \\
Europe & 5674 & 3493 & $61.6(60$ to 63$)$ \\
\hline Africa & 5914 & 1699 & $28.7(28$ to 30$)$ \\
\hline South Asia & 2315 & 549 & $23.7(22$ to 26$)$ \\
\hline Other regions & 387 & 223 & $57.6(53$ to 63$)$ \\
\hline Total & 14290 & 5964 & $41.7(41$ to 42$)$ \\
\hline
\end{tabular}

*Includes both recommended and non-standard drugs. Excludes 3359 case reports with no reported chemoprophylaxis information and 4285 with no birth place reported. confidence interval 6.3 to 8.5 ) per 1000 cases; we found no evidence of a significant change over the period of study. Case fatality was significantly lower among people travelling from the UK to visit friends or relatives in their own or their families' country of origin than among people travelling for other reasons $(0.25 \%$ $\left.v 1.9 \% ; \chi^{2}=83.1, \mathrm{P}<0.001\right)$.

\section{DISCUSSION}

This study of more than 39000 cases of malaria imported into the UK shows striking trends. $P$ falciparum malaria has increased steadily, which is a concern because these cases are potentially fatal; every year wholly preventable deaths do ensue in the UK. Reported cases are not distributed evenly across the population but are heavily concentrated in communities with frequent travel to see friends and relatives, especially in west Africa. Travellers to Nigeria and Ghana, neither of which is a common tourist destination, account for half of all imported falciparum cases. A minority of travellers with malaria report having used any prophylaxis, and much of that used is inadequate. Whereas falciparum is increasing, vivax malaria imported into the UK has dropped dramatically. Vivax malaria is also a disease of people visiting friends and relatives; in contrast to falciparum malaria, most cases are in people who reside outside London.

Disproportional burden of malaria in west African diaspora These data represent a public health failing but also an opportunity. They show that health messages are not getting through to ethnic minority groups visiting friends and relatives, especially in west Africa. Targeting messages tailored to these groups is essential in primary care and public health; this should be possible and would have a substantial impact on malaria in the UK. A halving of malaria in people in the African diaspora visiting friends and relatives would reduce malaria in UK travellers by almost a quarter. People visiting friends or 


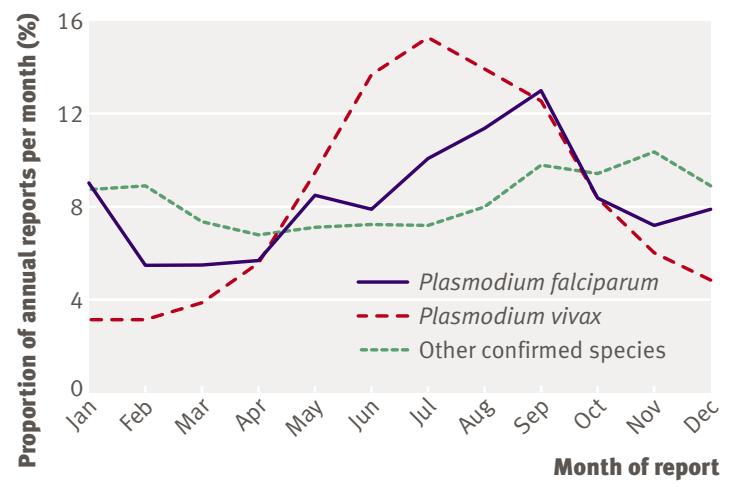

Fig 3 | Calendar month of onset of reported malaria in the UK, 1987 to 2006

relatives in their own or their families' country of origin may well expect to visit settings with a higher risk of transmission of malaria than other travellers and to do so for longer periods ${ }^{10-12}$; that many do this without the benefit of effective antimalarial chemoprophylaxis, as these and other data suggest, ${ }^{13-16}$ is of concern. Some evidence shows that people visiting friends or relatives in their own or their families' country of origin are less likely than tourists to self refer to travel health services before departure, ${ }^{17}$ are less likely to take up prophylaxis before they travel, ${ }^{18-20}$ and adhere less to preventive measures while abroad. ${ }^{21}$ The personal cost of recommended chemoprophylaxis and fears of side effects have been suggested as direct disincentives that disproportionately affect high risk groups. ${ }^{223}$ However, little information is available on the cultural and ethnic basis of knowledge, attitudes, and practice regarding malaria and its prevention. Beliefs among adult travellers born in Africa that they remain protected from the severe consequences of malaria and that malaria is a trivial complaint have been reported. ${ }^{2425}$
As the data reported here show, people of African origin do get malaria and indeed have a much higher risk of doing so than other travellers to Africa. Although these data are consistent with the findings of other studies that show travellers acquiring malaria on return to their country of origin to have a lower case fatality rate from malaria than other travelling groups, ${ }^{126}$ deaths do occur. ${ }^{27}$ Basing pre-travel advice on an assessment of the traveller's previous exposure to malaria cannot be justified, and falciparum malaria should always be managed as a preventable, potentially life threatening disease. ${ }^{328}$

\section{Disappearance of vivax cases imported from Asia}

Whereas the increase in falciparum cases from Africa can be explained by increases in travel to highly endemic countries, changes in travel volume cannot explain the decline in vivax malaria. The synchronous decrease in $P$ falciparum notifications from India and Pakistan suggests that the decreases are not simply due to differential notification or hospital admission policies for cases caused by different malaria species but probably reflect a true reduction in the risk of exposure to malaria during travel. Annual prevalence reports for malaria over the same period have documented modest declines in South Asia (thought to have resulted from vigorous local control efforts, increasing urbanisation, and rising economic prosperity), ${ }^{8-29}$ but nothing approaching the dramatic fall seen in cases imported to the UK and Europe. ${ }^{30}$ One explanation might be that travellers visiting family in the region increasingly stay in urban settings where local control measures have been most effective in reducing local transmission of malaria. In the light of the reduction in the risk of imported malaria from South Asia, the risk-benefit assessment of the routine advice on chemoprophylaxis for the region may need to be re-examined, as has been the case for Latin

\begin{tabular}{|c|c|c|c|c|c|c|c|c|c|c|}
\hline \multirow[b]{2}{*}{ UK region } & \multicolumn{5}{|c|}{ Reported malaria cases } & \multicolumn{5}{|c|}{$\begin{array}{l}\text { Reported cases per } 1000000 \text { population } \\
\text { (mid-year estimates, } 1987-2006)\end{array}$} \\
\hline & Pf & Pv & Po & $\mathrm{Pm}$ & All species & Pf & $\mathrm{Pv}$ & Po & $\mathrm{Pm}$ & All species \\
\hline \multicolumn{11}{|l|}{ England: } \\
\hline South west & 941 & 310 & 127 & 22 & 1419 & 9.7 & 3.2 & 1.3 & 0.2 & 14.7 \\
\hline South east & 3107 & 1287 & 354 & 85 & 4896 & 19.8 & 8.2 & 2.3 & 0.5 & 31.2 \\
\hline East of England & 1553 & 813 & 172 & 30 & 2604 & 14.7 & 7.7 & 1.6 & 0.3 & 24.7 \\
\hline West Midlands & 716 & 2263 & 71 & 9 & 3091 & 6.8 & 21.5 & 0.7 & 0.1 & 29.3 \\
\hline East Midlands & 378 & 451 & 48 & 12 & 906 & 4.6 & 5.5 & 0.6 & 0.1 & 11.0 \\
\hline $\begin{array}{l}\text { Yorkshire and the } \\
\text { Humber }\end{array}$ & 554 & 1003 & 74 & 14 & 1661 & 5.6 & 10.1 & 0.7 & 0.1 & 16.7 \\
\hline North west & 300 & 538 & 21 & 8 & 878 & 2.2 & 3.9 & 0.2 & 0.1 & 6.4 \\
\hline North east & 115 & 60 & 11 & 1 & 190 & 2.2 & 1.2 & 0.2 & 0.02 & 3.7 \\
\hline London & 15843 & 3463 & 1380 & 355 & 21345 & 112.1 & 24.5 & 9.8 & 2.5 & 151.0 \\
\hline Wales & 252 & 118 & 38 & 8 & 423 & 4.4 & 2.0 & 0.7 & 0.1 & 7.3 \\
\hline Scotland & 480 & 338 & 67 & 15 & 913 & 4.7 & 3.3 & 0.7 & 0.1 & 9.0 \\
\hline $\mathrm{N}$ Ireland & 73 & 37 & 9 & 1 & 120 & 2.2 & 1.1 & 0.3 & 0.03 & 3.6 \\
\hline Total & 24312 & 10681 & 2372 & 560 & 38446 & 20.8 & 9.1 & 2.0 & 0.4 & 32.9 \\
\hline
\end{tabular}

$\mathrm{Pf}=$ Plasmodium falciparum; Pm=Plasmodium malariae; Po=Plasmodium ovale; Pv=Plasmodium vivax.

*Excludes 854 cases with missing postcode. 


\section{WHAT IS ALREADY KNOWN ON THIS TOPIC}

Falciparum malaria is the most common potentially fatal tropical parasitic infection imported into the UK

Increased travel to areas endemic for malaria means that increasing numbers of UK residents are at risk

Effective prophylactic and anti-mosquito measures are available

\section{WHAT THIS STUDY ADDS}

Imported falciparum malaria has been increasing over the past 20 years, but vivax malaria has been decreasing markedly

Most malaria is in travellers visiting friends and relatives in their families' country of origin, especially in west Africa

Uptake of chemoprophylaxis is low in people who acquire malaria, especially travellers from migrant families, and tailoring health messages to migrant groups is a priority

America. ${ }^{31}$ Nevertheless, cases of malaria continue to occur and travellers need to be warned to have any fever investigated rapidly for malaria.

\section{Limitations of study}

The advantages of large scale, prospectively collected data from surveillance centres collected in an unchanged, standardised way over long periods are clear, but limitations also exist. Under-reporting is inevitable, ${ }^{32}$ and laboratories and clinicians differ in the comprehensiveness of their reporting. Previous studies of data from the Malaria Reference Laboratory suggest that they are more complete than most other routinely collected data on malaria and are in excess of $50 \%$ complete. ${ }^{4}$ Nevertheless, the true burden of malaria in the UK is almost certainly higher than these surveillance results suggest. As the methods did not change over this period, however, this is unlikely to affect trends reported here, particularly the relative increase in one species and decline in another seen in this study, or to explain the heavy concentration of cases in people visiting friends and relatives. Reporting clinicians often did not report information about travel history and prophylaxis, but we found no evidence to suggest that cases with missing information were systematically different from those with complete reports. Even when information about preventive measures is requested of travellers, adherence to such measures may be difficult to assess.

\section{Implications of findings}

This study highlights the need for general practitioners and people involved in public health to focus tailored messages on preventing malaria on members and descendants of migrant families visiting friends and relatives, especially in African migrant families. The UK has guidelines based on consensus that highlight the need for all UKresidents, irrespective of country of birth, to use effective antimalarial prophylaxis when visiting highly endemic areas. ${ }^{33}$ Changes to public health policy, including the current policy of charging for antimalarial prophylaxis, may need to be considered. Malaria is an almost entirely preventable, potentially fatal, disease that poses a considerable risk to some migrant groups.
We thank all the laboratories and clinicians who provide data to the Malaria Reference Laboratory.

Contributors: ADS, MB, and VS entered and analysed the data, with contributions from CJMW and RHB. DJB developed and supervised data collection up to 2003, and CJMW did so thereafter. ADS and CJMW drafted the paper, with contributions from all authors. CJMW is the guarantor Funding: CJMW is supported by the Gates Malaria Partnership, and DJB is a Leverhulme emeritus fellow. All other support is from the Health Protection Agency.

Competing interests: None declared

Ethical approval: Not needed.

Provenance and peer review: Not commissioned; externally peer reviewed.

1 Snow RW, Guerra CA, Noor AM, Myint HY, Hay SI. The global distribution of clinical episodes of Plasmodium falciparum malaria. Nature 2005;434:214-7.

2 World Tourism Organization. WTO World Tourism Barometer 2005;3(1).

3 Moore DA, Grant AD, Armstrong M, Stumpfle R, Behrens RH. Risk factors for malaria in UK travellers. Trans R Soc Trop Med Hyg 2004;98:55-63

4 Davidson RN, Scott IA, Behrens RH, Warhurst D. Under-reporting of malaria, a notifiable disease, in Britain. I Infect 1993;26:348-9.

5 Northern Ireland Statistics and Research Agency. Publications: population and migration. www.nisra.gov.uk/publications/default. asp10.htm.

6 Office for National Statistics. www.statistics.gov.uk.

7 General Register Office for Scotland. Population: information and statistics. www.gro-scotland.gov.uk/statistics/population/index. html.

8 World Health Organization. World malaria report 2005. Geneva: WHO, 2005.

9 Office for National Statistics. International passenger survey. www. statistics.gov.uk/ssd/surveys/international_passenger_survey.asp.

10 Schlagenhauf P, Steffen R, Loutan L. Migrants as a major risk group for imported malaria in European countries. J Travel Med 2003;10:106-7.

11 Angell SY, Behrens RH. Risk assessment and disease prevention in travelers visiting friends and relatives. Infect Dis Clin North Am 2005;19:49-65.

12 Bouchaud O, Cot M, Kony S, Durand R, Schiemann R, Ralaimazava P, et al. Do African immigrants living in France have long-term malarial immunity? Am J Trop Med Hyg 2005;72:21-5.

13 Research Group on Imported Infectious Diseases. TropNetEurop sentinel surveillance report: falciparum malaria in 2004. University of Munich,

2005 (available at www.tropnet.net/reports friends/ pdf_reports_friends/mar05_falcmal2004_friends.pdf)

14 Jelinek T, Schulte C, Behrens R, Grobusch MP, Coulaud JP, Bisoffi Z, et al. Imported falciparum malaria in Europe: sentinel surveillance data from the European network on surveillance of imported infectious diseases. Clin Infect Dis 2002;34:572-6.

15 Robinson P, Jenney AW, Tachado M, Yung A, Manitta J, Taylor K, et al. Imported malaria treated in Melbourne, Australia: epidemiology and clinical features in 246 patients. J Travel Med 2001;8:76-81.

16 Casalino E, Le Bras J, Chaussin F, Fichelle A, Bouvet E. Predictive factors of malaria in travelers to areas where malaria is endemic. Arch Intern Med 2002;162:1625-30.

17 Scolari C, Tedoldi S, Casalini C, Scarcella C, Matteelli A, Casari S, et al. Knowledge, attitudes, and practices on malaria preventive measure of migrants attending a public health clinic in northern Italy. I Travel Med 2002;9:160-2.

18 Phillips-Howard PA, Radalowicz A, Mitchell J, Bradley DJ. Risk of malaria in British residents returning from malarious areas. $B M$ 1990;300:499-503.

19 Dos Santos CD, Anvar A, Keystone JS, Kain KC. Survey of use of malaria prevention measures by Canadians visiting India. CMAJ 1999;160:195-200.

20 Semaille C, Santin A, Prazuck T, Bargain P, Lafaix C, Fisch A. Malaria chemoprophylaxis of 3,446 French travellers departing from Paris to eight tropical countries. I Travel Med 1999;6:3-6.

21 Pistone T, Guibert P, Gay F, Malvy D, Ezzedine K. Malaria risk perception, knowledge and prophylaxis practices among travellers of African ethnicity living in Paris and visiting their country of origin in sub-Saharan Africa. Trans R Soc Trop Med Hyg 2007;101:990-5.

22 Badrinath P, Ejidokun OO, Barnes N, Ramaiah S. Change in NHS regulations may have caused increase in malaria. $B M$ 1998:316:1746-7.

23 Evans M. Adverse events with mefloquine: patients may start to take cheaper over the counter regimens [letter]. BMJ 1996;313:1554.

24 Leonard L, Van Landingham M. Adherence to travel health guidelines: the experience of Nigerian immigrants in Houston, Texas. J Immigr Health 2001;3:31-45. 
25 Morgan M, Figueroa-Munoz J. Barriers to adherence and uptake with malaria prophylaxis by the African community in London, England: a focus group study. Ethn Health 2005;10:355-72.

26 Matteelli A, Colombini P, Gulletta M, Castelli F, Carosi G. Epidemiological features and case management practices of imported malaria in northern Italy 1991-1995. Trop Med Int Health 1999;4:653-7.

27 Reid AJ, Whitty CJ, Jennings RM, Bovill BA, Behrens RH, Bryceson AD, et al. Malaria at Christmas: risks of prophylaxis versus risks of malaria. BMJ 1998;317:1506-8.

28 Bunn A, Escombe R, Armstrong M, Whitty CJ, Doherty JF. Falciparum malaria in malaria-naive travellers and African visitors. QJM 2004;97(10):645-9.

29 World Health Organization. Regional Office for South-East Asia. Malaria: disease burden in SEA region. 2007. www.searo.who.int/ EN/Section10/Section21/Section340_4018.htm.
30 Behrens RH, Bisoffi Z, Bjorkman A, Gascon J, Hatz C. Malaria prophylaxis policy for travellers from Europe to the Indian Sub Continent. Malar J 2006;5:653-7.

31 Behrens R, Carroll B, Beran J, Bouchaud O, Hellgren U, Hatz C, et al. The low and declining risk of malaria in travellers to Latin America: is there still an indication for chemoprophylaxis? Malar / 2007;6:114.

32 Van Hest N, Smit F, Verhave J. Underreporting of malaria incidence in the Netherlands: results from a capture-recapture study. Epidemiol Infect 2002;129:371-7.

33 Chiodini P, Hill D, Lalloo D, Lea G, Walker E, Whitty CJM, et al. Guidelines for malaria prevention in travellers from the United Kingdom. London: Health Protection Agency, 2007 (available at www.hpa.org.uk/web/HPAwebFile/HPAweb_C/ 1203496943523).

Accepted: 2 May 2008 